\title{
Rede de Relações Interorganizacionais no Campo Organizacional de Videira-SC
}

\author{
Clóvis L. Machado-da-Silva \\ Claudia Coser
}

\begin{abstract}
ResUMo
O objetivo do presente artigo foi o de verificar as relações interorganizacionais entre 40 organizações do município de Videira, no Estado de Santa Catarina, a partir de uma organização focal. Essas organizações interagem em um sistema de produção agroindustrial que envolve um complexo processo de estruturação econômica, política e social, considerado no tempo e espaço social. Procurou-se avaliar a influência da organização focal - que coordena a priori os esforços de produção agroindustrial - sobre as estruturas institucionais regulativas, normativas e cognitivas, o que implicou analisar a recorrência e a simultaneidade dos mecanismos isomórficos coercitivo, normativo e mimético no campo organizacional em estudo. As relações de cooperação, competição e conflito entre as organizações que integram a rede em exame foram avaliadas com base na noção de campo organizacional como campo de poder, de estruturas cognitivas e de significação sociocultural. Os resultados demonstram diferentes esferas e níveis de influência da organização focal sobre as estruturas institucionais, com implicações para a ocorrência de isomorfismos nas organizações, o que ressalta a importância de uso de uma perspectiva multiparadigmática para o entendimento e o tratamento do conceito de campo organizacional.
\end{abstract}

Palavras-chave: teoria institucional, estruturação, campo organizacional, isomorfismo, relações interorganizacionais.

\begin{abstract}
The objective of this article was to verify the interorganizational relationships between forty organizations in the town of Videira in Santa Catarina State from an organizational focus. These organizations interact in a system of agroindustrial production which involves a complex process of economic, political and social structuring in social time and space. The goal was to evaluate the influence of the focal organization, which a priori coordinates agroindustrial production efforts, on the regulative, normative and cognitive institutional structures, which meant analyzing the recurrence and simultaneousness of the isomorphic, coercive, normative and mimetic mechanisms in the organizational field under study. The relationships of cooperation, competition and conflict among the organizations that make up the network under study were evaluated based on the notion of organizational field as a field of power, cognitive structures and socio-cultural significance. The results show different levels and spheres of influence of the focal organization on institutional structures, with implications for the occurrence of isomorphisms in organizations, which highlights the importance of the use of a multiparadigmatic perspective for the understanding and the treatment of the concept of organizational field.
\end{abstract}

Key words: institutional theory, structuring, organizational field, isomporphism, interorganizational relationships. 


\section{INTRODUÇÃO}

As redes interorganizacionais assumem importância na medida em que têm a capacidade de regular interdependências transacionais mais complexas bem como apresentar movimentos para a cooperação, competição e conflitos. A literatura acerca das redes sociais tem apresentado preocupações mais estruturais (Guler, Guillen \& Macpherson, 2002), em muitos estudos tem-se observado a utilização de conceitos como equivalência estrutural e posições dos atores para se explicar a difusão de ações entre atores de um dado grupo social. Algumas configurações associadas a aspectos estratégicos, de tomadas de decisão, poder e controle bem como estruturas de governança são mais enfocadas pelas perspectivas de Custos de Transação e Institucional.

O termo rede por si mesmo é uma noção abstrata que se refere a um conjunto de nós conectados por relacionamentos. Na teoria das organizações o emprego da noção de redes torna-se aplicável quando denotam modos de coordenação, diferenciação e integração entre unidades organizacionais especializadas, tendo em vista que nas relações econômicas, organizações são precedidas por relações sociais. Distritos industriais, por exemplo, são salientes versões de redes sociais que viabilizam pólos industriais bastante competitivos. Daí a importância do que Bourdieu (1986) denominou de capital social - "um agregado de recursos potenciais ou atuais associados a possessão de duráveis redes de relacionamento, reconhecimento e comprometimento mútuo" (p. 249). Lin (2001) apresentou uma definição de capital social baseada em recursos, que estariam embebidos nas redes sociais, sendo acessados e utilizados pelos atores para ações.

Castells (1996) argumentou que o processo de globalização provoca um aniquilamento do espaço pelo tempo. O espaço estaria estruturado dentro de espaços de redes. O tempo tem sido mudado sob as condições da revolução digital, a qual tornou possível o desenvolvimento de uma lógica de rede, que prevê complexidade de interações e padrões imprevisíveis. Dessa maneira a lógica e o significado dos lugares passa a ser absorvida pelas redes. A estabilidade e a estrutura aqui são mais aparentes do que reais.

Elites dirigentes desenvolvem para si mesmos uma rede de espaços defensíveis, segregados localmente e globalmente interconectados. O discurso de Castells e Latour, para Sheppard (2002) apresentou as redes como emergentes ou negligenciadas formas de organização social, com distintas feições e espacialidade interna que as tornam superiores aos mercados e hierarquias. $\mathrm{O}$ enfoque de 
Castells (1996) sobre as redes globais que constituem o espaço de fluxos sugere que as redes, expandidas horizontalmente através do espaço, estão refazendo a geografia da globalização.

É constatado que os estudos das relações interorganizacionais têm sido conduzidos por métodos basicamente empíricos, quantitativos, e de corte transversal respectivamente (Oliver, 1998). De acordo com a autora, os estudos de redes interorganizacionais têm estado situados entre a perspectiva de redes sociais em um pólo e a de governança em outro. A primeira emprega o aparato formal da análise de redes sociais examinando como as propriedades estruturais das redes bem como as posições dentro dessas redes influenciam as organizações e seus membros; enquanto que a segunda lida com os mecanismos institucionais pelos quais os relacionamentos são iniciados, negociados, planejados, coordenados, adaptados e limitados. Essa perspectiva se concentra nos atributos dos atores da rede e na forma e conteúdo dos seus relacionamentos dentro de um contexto institucional particular - tem apontado como as condições políticas, legais, culturais e industriais provocam impacto na formação e na forma das redes interorganizacionais. A abordagem institucional também lida com as relações de dependência entre as organizações de um dado campo organizacional, porém esta dependência não se refere a recursos materiais ou transações, mas aos recursos chave para a legitimidade, importante suporte para a sobrevivência organizacional (DiMaggio, 1986).

As organizações estabelecem relações para compartilhar conhecimento, atingir objetivos em conjunto e obter recursos materiais e imateriais, de maneira cooperativa, competitiva, conflitiva ou harmoniosa (Aiken \& Hage, 1968), e que podem ser estudas a partir da análise de redes, uma constelação de diversas metodologias estratégicas para investigação de uma estrutura social, trabalhando com certa base de pressuposições teóricas e premissas (Emirbayer \& Goodwin, 1994). A perspectiva da rede promoveria sensibilidade à variedade e complexidade de interações que sustentam a atividade organizada dentro de um dado ambiente, o qual não pode ser compreendido adequadamente pela observação de comportamentos individuais, mas de padrões relacionais (Berkowitz, 1982; Burt, 1983; Hatch, 1997; Knoke \& Laumann, 1982; Mitchell, 1976), embutidos em texturas institucionais (Casson \& Cox, 1999; Stevenson \& Greenberg, 2000; Stuart, 1999).

A análise do conteúdo das ligações interorganizacionais desencadeadas e estruturadas em um dado contexto social pode ser apoiada nos pressupostos da abordagem institucional. No referido estudo, o campo organizacional surge como um nível de análise apropriado, dado fato de contemplar os aspectos estruturais que valorizam construções simbólicas desenvolvidas e exteriorizadas a partir da constante interpretação e interação entre os atores envolvidos. 


\section{BASE TEÓRICO-EMPÍRICA}

Reconhecida a necessidade de uma estrutura teórica, para suporte das inferências da análise de redes, têm-se dentre mais de 16 teorias a abordagem institucional (Oliver, 1998), que oferece a possibilidade analítica acerca do ambiente e das estruturas advindas das relações entre as organizações dentro de um sistema social, e que a partir destas definem e redefinem recursivamente as estruturas institucionais - regulativas, normativas e cognitivas - num processo de constante interpretação e interação de padrões instituídos e veiculados pela cultura, estrutura social e rotinas, que passam a orientar a ação dos atores envolvidos num dado contexto institucional de sistemas culturais complexos (Mizruchi \& Galaskiewicz, 1994; Scott, 1995).

As estruturas institucionais regulativas constrangem e regulam o comportamento por meio de regras, monitoramento, sanções e punições de maneira formal. A legitimidade das ações dos atores está associada ao cumprimento destes requerimentos (Scott, 1995), reduzindo as incertezas entre os atores da rede quanto às suas ações, na medida em que as interações vão compartilhando significados (March \& Olsen, 1989; Kiun, 2001) que são alterados ou reproduzidos mediante as interações entre os participantes num processo de interpretação constante da realidade (Berger \& Luckmann, 1985). Quanto às estruturas normativas, introduzem uma dimensão prescritiva, avaliativa na vida social, incluindo valores e normas que definem os significados legítimos para fins validados (Scott, 1995), enraizados na lógica do adequado (March \& Olsen, 1989) perfazendo a rotina dos atores da rede em diferentes posições e papéis sociais, revelando aspectos morais e alinhamento cultural. As estruturas cognitivas também sustentam significados que são compartilhados entre os atores acerca das estruturas regulativas e normativas, ou seja da realidade que cerca os atores, que constróem e continuamente negociam a realidade social, num contexto que contempla estruturas simbólicas, objetivas e externas que oferecem orientação, para as ações ao tempo que servem como categorias para o pensar e o agir, bem como de base para a construção da identidade dos atores (Scott, 1995). Como consequiência, as interações ficam mais complexas entre os atores (organizações, pessoas) atribuindo ao contexto característica dinâmica, pouco determinística ( $\mathrm{Li}$ \& Berta, 2002), pois a interação entre os atores/agentes constituintes e constituídos de estruturas de significado compartilhada proporciona a constante interpretação dos padrões de ação instituídos. Para Machado-da-Silva, Fonseca e Crubellate (2005) "estrutura, agência e interpretação são mais apropriadamente tratadas quando definidas como elementos fundamentais da institucionalização como processo recorrente" (p. 12). 
DiMaggio e Powell (1991) apontou que o processo de estruturação nas redes possui quatro etapas: aumento de interação entre as organizações; emergência de características definidas de coalizões e estrutura de dominação; aumento na carga de informação com organizações que têm de lidar; e formação da consciência nas organizações de que elas estão comprometidas com empreendimentos comuns, podendo adotar posturas estruturalmente isomórficas (DiMaggio \& Powell, 1983). Esses autores enfatizam o isomorfismo estrutural como importante conseqüência de processos competitivos e institucionais, conceituando importantes mecanismos - coercitivo, mimético e normativo - pelos quais efeitos institucionais são difundidos através de um campo organizacional mediante forças técnicas e institucionais (Scott \& Meyer, 1994).

O isomorfismo coercitivo, de acordo com DiMaggio e Powell (1983), é resultante de pressões formais e informais exercidas por uma organização sobre outra que se encontra em condição de dependência. Quanto ao isomorfismo mimético, constitui na "adoção por parte de determinada organização, de procedimentos e arranjos estruturais implementados por outras organizações, com a finalidade de reduzir a incerteza ocasionada por problemas tecnológicos, objetivos conflitantes e exigências institucionais" (DiMaggio \& Powell, 1983). Referindo-se ao isomorfismo normativo, esses autores apontam que o grau de profissionalização é o fator mais importante como mecanismo normativo a ser considerado para o entendimento das pressões normativas do ambiente. A profissionalização envolve o compartilhamento de um conjunto de normas e rotinas de trabalho pelos membros de uma determinada ocupação (Machadoda-Silva \& Fonseca, 1996).

As estruturas institucionais e os isomorfismos podem ser desencadeados dentre as fronteiras de um campo organizacional, onde organizações sob influências estruturais bastante próximas, principalmente na medida em que o campo está mais estruturado, melhor definido, maturado. O contexto do campo organizacional é reconhecido como o nível de análise mais adequado para a compreensão da interação entre a evolução do campo estrutural e a mudança nas práticas institucionais (Scott, 1998). Um campo organizacional conota a "existência de uma comunidade de organizações que compartilha sistemas de significados comuns" (Scott, 1995, p. 56), o que leva à adoção de estruturas, processos e práticas uniformizados ao ambiente institucional, pressupondo certa estabilidade, a qual pode ser rompida a partir de tentativas de inovações de natureza técnica, incidindo em consideráveis custos no que se refere a legitimidade das ações (Meyer \& Rowan, 1977; Morgan, 1996). Para Machado-da-Silva, Fonseca e Crubellate (2005) "embora padrões institucionais limitem a possibilidade de ação racional, são os mesmos padrões que, concomitantemente, possibilitam alguma ação, e assim, alguma racionalidade.” (p. 21). 
As análises de campo organizacional podem ser elaboradas com o aparato metodológico da análise de redes, com o qual podem ser enfatizadas as relações entre os atores e a estruturação destas no campo. Desta forma os conceitos de campo organizacional, estruturas institucionais e isomorfismos comporiam o que podemos denominar de conteúdo das relações que a priori se processam dentro de padrões de relações previstos a partir de estruturações sociais. As relações entre atores de um campo organizacional podem ser de natureza bastante diversa, podendo conter entre outros: conflito, competição, cooperação e relações de poder, os quais constituem interações que interferem nas definições e redefinições das estruturas institucionais e dos isomorfismos, compreendendo as estruturas como mutuamente constitutivas da ação e por esta constituída (Giddens, 1989).

Para Leblebici, Salancik, Copay e King (1991), as convenções institucionalizadas, apesar de resolverem problemas, produzem resultados que não se constituem em vantagem para todos os atores participantes do campo organizacional, intensificando a competição por recursos institucionalizados, adicionado ao fato de que são os atores dominantes quem determinam e encorajam as novas práticas. Amburgey e Dacin (1994) sugerem que uma série de mudanças incrementais estratégicas podem produzir grande efeito sobre a eficiência ou grau de competitividade das organizações. Pondera Powell (1991) que os processos competitivos e institucionais não são necessariamente opostos.

A existência de conflito num campo organizacional também pode desencadear mudanças instititucionais. Jepperson (1991) distingue quatro tipos de processos de mudança institucional: a formação institucional, desenvolvimento institucional, desinstitucionalização e reinstitucionalização. Os conflitos sociais também ocorrem a partir das lutas entre atores, que mobilizam recursos de poder e sanção para dar procedência aos interesses, crenças, decisões e ações, ou também para dar prioridade a um sistema de regras sobre outro, ou para manter posições (Bourdieu \& Wacquant, 1992). Nas relações interorganizacionais, tanto a cooperação quanto o conflito são inevitáveis e necessários à manutenção da vida de uma rede Dubois e Hakansson (1999).

Dryzek (1996) afirma que as instituições estão muito atreladas ao discurso, e a estrutura institucional consiste numa questão de redesenhar a constelação de discursos dominantes na sociedade, presentes nas relações de poder. $\mathrm{O}$ discurso sobre o que é adequado acontece subjetivamente, mas é solidificado na ação, objetivamente. Também para Foucault (1987), a disciplina e as instituições exercem poder por meio da normatização de procedimentos e da constante vigilância. $\mathrm{O}$ conhecimento é a operação da disciplina, provendo bases para ação (Knights, 1992; Townley, 1993). O foco é saber como as práticas disciplinares, a lógica e a racionalidade operam para criar ordem, conhecimento e propriedades de poder, 
transferíveis em diferentes domínios. Pode-se afirmar que as relações de poder estão intimamente atreladas à estruturação das relações e às estruturas institucionais, principalmente no que tange a reprodução de estruturas regulativas e normativas, estando relacionado à preservação histórica de padrões de valores, os quais refletem as posições de atores na estrutura social (Brint \& Karabel, 1991; Fligstein, 1991). A compreensão de que o poder não é uma propriedade de alguém ou de um grupo, mas um aspecto da real ou potencial interação entre atores sociais também é compartilhada por Fligstein (1991) e Knoke (1994). Para Pfeffer (1982), a teoria do poder e conflito é ainda útil para predizer as dinâmicas das relações cooperativas.

Para Smith, Carroll e Ashford (1995), muitas definições de cooperação enfocaram processos pelos quais atores, grupos se unem, interagem e formam relações para ganhos ou benefícios mútuos. Ring e Van de Ven (1994) definem a cooperação de forma dinâmica, incluindo a disposição dos atores em continuar as relações cooperativas, que são mecanismos socialmente construídos para a ação coletiva, que é continuamente reestruturada por ações e interpretações simbólicas das partes envolvidas.

Elucidados alguns fenômenos desencadeados nas relações interorganizacionais, pode-se afirmar que o estudo carece de suporte metodológico e teórico que considere as estruturações das relações do campo organizacional. Atribui-se a um sistema social uma série de padrões estruturais e de relação, desenvolvidos a partir da interação entre os atores organizacionais. Pode-se afirmar que a rede é atualmente a imagem que mais se aproxima do desenho das relações organizacionais.

Principia-se pelas definições de algumas variáveis estruturais do campo organizacional, tais como: a centralidade da rede, que pressupõe que os atores do centro da rede são estruturalmente dominantes. Está associada ao grau em que um ator está envolvido em todas as relações no sistema (Galaskiewicz, 1979; Knoke \& Burt, 1983); a posição dos atores na rede ou à hierarquia da rede, consistem para Knoke (1994) e Marsden e Friedkin (1994) em duas técnicas - a equivalência estrutural e subgrupos de coesão. Na equivalência estrutural, dois ou mais atores conjuntamente ocupam uma posição equivalente na estrutura, tendo alguns padrões de relação com os outros atores No critério de subgrupos de coesão, a união acontece apenas entre atores que mantêm interações mútuas e densas; são grupos chamados também de cliques, compostos de no mínimo 3 atores (Burt, 1983; Marsden \& Friedkin, 1994; Borgatti \& Everett, 1992). Quanto às semelhanças estruturais, Marsden e Friedkin (1994), afirmaram que, quando os atores estão diante de situações ambíguas, tendem a se apoiar por orientações normativas pela comparação de suas atitudes com a atitudes de atores de grupos 
semelhantes, ou ainda, de atores que estão na mesma posição social, com papéis sociais semelhantes, denotando assim padrões de relacionamento (Pattison, 1994); a densidade da rede é obtida pela proporção do número de nós ou ligações observados para o número de nós possíveis teoricamente (Granovetter, 1976; Mitchell, 1976); quanto à intensidade da rede consiste no grau em que atores estão preparados para cumprir obrigações, ou sentir-se livre para exercer os direitos implícitos na sua relação com outros atores (Mitchell, 1976); a verificação da frequência dos contatos entre os atores num dado espaço de tempo também contribui para as análises da estruturação e dos padrões de relações entre os atores do campo, não significando necessariamente em intensidade de relações (Knoke, 1994; Mitchell, 1976).

\section{Considerações Metodológicas}

Os propósitos do estudo estão centrados na análise de diversos elementos que compõem a praxis do referido campo organizacional: (1) estruturas institucionais regulativas, normativas e cognitivas; (2) isomorfismos coercitivo, normativo e mimético; (3) competição; (4) relações de poder; (5) conflitos. É necessário ressaltar a importância da configuração estrutural do referido campo organizacional. Para tanto, algumas variáveis associadas à análise de redes são levantadas: tamanho; densidade; intensidade; frequência das relações; padrões de relacionamento; e equivalência estrutural. O campo organizacional é composto por 40 organizações que desenvolvem atividades basicamente com a finalidade de dar suporte a um ciclo produtivo agroindustrial orquestrado por uma organização focal, no município de Videira, Santa Catarina. As organizações do campo são de natureza bastante diversa no que tange as relações com a organização focal (fornecedores de produtos e serviços, governo municipal, sindicatos, organizações financeiras, universidade, hotéis, empresas de comunicação, e organizações públicas de captação e capacitação de recursos humanos). Os atores entrevistados no estudo podem ser caracterizados dentro de perfis como fundadores, diretores, gerentes, coordenadores, secretários municipais e vereadores.

À realização do estudo foi necessária a associação de diversos instrumentos de coleta e análise dos dados. Os dados primários consistem em entrevistas semiestruturadas com pelo menos um ator-chave (estratégico) de cada organização, bem como entrevistas com atores transeuntes, nas ruas da cidade. Análises de conteúdo (SPHINX) e discursiva (Spink, 1999) desses serviram de suporte para 
as inferências do estudo, acompanhadas de análise de conteúdo e documental de dados secundários extraídos de diferentes registros (jornais, revistas, leis, contratos, arquivos históricos). Para estruturação da rede de relações foi necessária a aplicação de questionário fechado, resultando em matrizes que foram analisadas com o software UCINET 6 (Borgatti, Everett \& Freeman, 2002), que dispõe de algorítmos que auxiliam na compreensão estrutural da referida rede.

A perspectiva do estudo é de natureza transversal; porém a investigação recorre a acontecimentos passados, resgatados por meio das entrevistas e dos dados secundários. O nível de análise da pesquisa é a rede interorganizacional ou o campo organizacional, sendo a unidade de análise cada ator organizacional da rede.

\section{Apresentação e AnÁlise}

Conforme foi exposto, o referido campo organizacional possui características que constituem um arranjo em torno de uma atividade local e regional, a agroindústria, orquestrada por uma organização focal - a Alpha - a qual absorve a maioria dos esforços de produção e serviços das outras 39 organizações levantadas a partir da técnica snowball (enumeradas pela organização focal). Cada interação entre as organizações do campo representa uma intenção de estabilizar as transações das organizações por meio de alguma ligação interorganizacional, bem como utilizar estes vínculos para ter acesso a recursos, estabilizar resultados e desviar do controle ambiental (Pfeffer, 1982).

Diante do exposto cabe então definir alguns fatores que constituem o que se denomina no estudo, de estruturação da rede ou do campo organizacional: tamanho e densidade da rede, razões do relacionamento, base predominante das relações, intensidade e importância das interconexões para os atores, as atividades realizadas em conjunto e grau de centralidade da rede, a serem especificados.

Há que se considerar juntamente com o tamanho da rede organizacional a complexidade deste no que concerne à diversidade dos atores (Dubois \& Hakansson, 1999). O tamanho da rede é de 39, consistindo no número de vínculos diretos ou o número de linhas que são incidentes entre as unidades individuais da rede (Knoke \& Laumann, 1982; Wasserman \& Faust, 1999). A questão utilizada para determinar os nós (nodes) da rede, e respondida pelos 40 atores é: apontar a partir da lista (40 atores) quais são as organizações com as quais a sua organização se relaciona. $\mathrm{O}$ tamanho da rede então é mensurado a partir do conceito da nomenclatura degree (máximo 39, mínimo 7, e média 24). 
A densidade das relações do campo organizacional, medida a partir do cálculo da proporção das linhas incidentes ou possíveis com os nós de um gráfico (Degenne \& Forsé, 1999; Granovetter, 1976; Scott, 2000; Wasserman \& Faust, 1999). Há que se considerar o perigo do cálculo da densidade total da rede em análise $(0,49)$, devido ao grande número de atores e a sua diversidade (Scott, 2000).

Com a intenção de diminuir esses riscos, as análises da rede de relações do campo organizacional foram vistas sob a perspectiva total e parcial, dividido em três grupos: central (6 atores) ; intermediário (26 atores); periférico (8 atores). Esta divisão foi obtida a partir da questão: Como você qualifica a importância do relacionamento da sua organização com as que compõem a lista (com as quais a organização está relacionada)? São considerados para efeito de cálculo, os valores atribuídos pelos atores a cada organização com a qual se tem relacionamento dentro de uma escala ordinal positiva: 1 (sem importância); 2 (pouco importante); 3 (importante); 4 (muito importante) e; 5 (crucial). Através da soma dos vetores da matriz resultante desta questão, são classificados os grupos a partir dos resultados extremos e intermediários, ou seja, as organizações que obtiveram resultado maior que 100 são consideradas no estudo como centrais, aquelas com resultados inferiores a 30 são periféricas, e aquelas com resultado entre 31 e 99 compreendem ao grupo intermediário. Ficando estabelecida a seguinte configuração: Centro (3 671920 34); Intermediário (1 2458910111213 141516182122252627283335363738 39); Periferia (17 2324293031 $3240)$.

A divisão da rede de relações do campo organizacional em análise nesses três níveis explicita o desenho das relações entre os atores. Na Tabela 1 estão expostos os graus de densidade para cada grupo.

\section{Tabela 1: Densidade das Relações Inter-Grupos}

\begin{tabular}{|l|c|c|c|}
\hline & Centro & Intermediário & Periferia \\
\hline Centro & 1,0 & 0,86 & 0,89 \\
\hline Intermediário & 0,85 & 0,49 & 0,10 \\
\hline Periferia & 0,70 & 0,23 & 0,10 \\
\hline
\end{tabular}

Fonte: Dados Primários

Embora a densidade de todo o campo seja de 0,49 (metade das relações possíveis), este valor é próximo apenas no grupo de atores que se situam na faixa intermediária da rede, o que significa na não representação adequada dos dois extremos. As relações entre os atores do centro estão em nível máximo de densidade, formando um gráfico completo $(1,0)$ e coesas (geodesic distance). Quanto ao grupo intermediário, apresenta um número elevado de atores, o que 
parece ser atípico para as configurações de redes (Scott, 2000). Outro fato interessante diz respeito ao grau de densidade apresentada no grupo $(0,51)$, elevado para um grupo intermediário, composto de organizações com tempo de existência médio de 12 anos, e apresentando um grau de coesão (geodesic distance) significativo $(0,75)$. Pode-se afirmar que neste grupo (intermediário) se efetivam a institucionalização e disseminação de estruturas institucionais regulativas, normativas e cognitivas, geradas a partir das relações com a organização focal, situada no grupo central. As relações entre os atores da periferia revelam baixa densidade $(0,12)$ e pouco recíprocas, o que facilita a ruptura dessas relações (Walker, Wasserman \& Wellman, 1994), além de estarem expostos ao "abuso oportunista" (Laat, 1999, p. 167). As relações entre o grupo periférico, composto basicamente por transportadores, estão enfraquecidas e não estruturadas, provocando assim ações isoladas e marcadas pela competição.

Na Tabela 2 está ilustrada a configuração da importância que os atores de cada grupo atribuem às relações que estabelecem sendo: 1 (sem importância); 2 (pouco importante); 3 (importante); 4 (muito importante) e; 5 (crucial).

\section{Tabela 2: Importância das Relações no Interior dos Grupos}

\begin{tabular}{|c|c|c|c|}
\hline & Centro & Intermediário & Periferia \\
\hline $\mathbf{1}$ & 0 & 3 & 29 \\
\hline $\mathbf{2}$ & 3 & 21 & 43 \\
\hline $\mathbf{3}$ & 30 & 54 & 29 \\
\hline $\mathbf{4}$ & 50 & 20 & 0 \\
\hline $\mathbf{5}$ & 17 & 2 & 0 \\
\hline
\end{tabular}

Fonte: Dados Primários

As relações estabelecidas entre os atores do centro são consideradas para a metade do grupo como muito importantes. Quanto ao grupo intermediário, as relações são consideradas por $54 \%$ dos atores como importantes. Este número pode ser utilizado para corroborar com inferências que denunciam estar neste grupo a concentração e a difusão das estruturas institucionais normativas e cognitivas, e principalmente, que é a partir deste grupo que surgem inovações, bem como novos focos para os isomorfismos normativo e mimético para todo o campo organizacional. Além disso, o grau de coesão associado aos indícios de semelhança e identificação, apontados nas entrevistas, no que tange à trajetória, fundação, tamanho, idade e condições de relação com a organização focal.

Um outro fator a ser analisado no referido campo organizacional está relacionado à frequiência das relações estabelecidas entre os atores, a qual foi operacionalizada a partir da questão: se a sua organização mantém algum tipo de contato com 
alguma das organizações da lista, apontar a periodicidade destas relações. As respostas são de natureza ordinal inversa, ou seja: 1 (diário); 2 (semanal); 3 (mensal); 4 (semestral); 5 (anual). A partir da Tabela 3 demonstra-se a freqüência dos relacionamentos dentro de cada um dos grupos.

\section{Tabela 3: Freqüência Relações Intra-Grupos}

\begin{tabular}{|l|c|c|c|}
\hline & Centro & Intermediário & Periferia \\
\hline 1 - diário & 40 & 15 & 29 \\
\hline 2 - semanal & 3 & 21 & 43 \\
\hline 3 - mensal & 57 & 34 & 29 \\
\hline 4 - semestral & 0 & 19 & 0 \\
\hline 5 - anual & 0 & 10 & 0 \\
\hline
\end{tabular}

Fonte: Dados Primários

Nota-se que as relações entre os atores do centro estão divididas entre as frequiências mensal e diária, significa que além de densas e coesas as relações são freqüentes, mas ainda não se pode afirmar que são intensas. No nível intermediário, as relações estão bastante distribuídas, o que indica também uma diversidade e riqueza na natureza e conteúdo das relações. Os benefícios desta relação, na concepção de Burt (1995) são basicamente a informação e o controle. Porém, é destacada a necessidade de se dispensar tempo e energia para adicionar contatos não redundantes (structural hole), obtendo diversidade de fontes de informações e recursos. Uma rede densa pode ser vantajosa até o ponto em que todos os atores compartilham das mesmas informações e recursos. Hagedoorn e Duysters (2002) afirmaram que as redes muito densas por definição envolvem considerável grau de interação entre os atores, mas que muitas destas interações são, além de redundantes, ineficientes. Tem-se por um lado o centro, que obtém vantagens pela densidade e freqüência, como o compartilhamento e controle de informações e recursos e por outro um grupo intermediário que pode beneficiarse da riqueza em termos de diversidade das relações, bem como de abertura para atores de outras redes, gerando relações não redundantes (Burt, 1995), as quais trazem para dentro do campo organizacional insumos para a definição e redefinição de novas estruturas normativas e principalmente cognitivas, influenciando desta forma, nos isomorfismos normativo e mimético. Quanto ao grupo periférico, as relações também se apresentam distribuídas entre diário, semanal e mensal, constituindo num grupo pouco representativo para inferências acerca desta variável. Pode-se afirmar que as relações densas e freqüentes da organização focal com os demais atores da rede também consistem em indicadores importantes para inferências com relação às estruturas institucionais no campo, dado ao constante reforço e manutenção de padrões de ação e de interpretação dos atores. 
A intensidade das relações é definida no estudo como o grau em que os atores estão dispostos a cumprir obrigações, ou seja, a demonstração de liberdade para exercer os direitos implícitos na sua relação com os outros atores (Mitchell, 1976). A variável foi operacionalizada a partir das entrevistas com os atores bem como via resposta de questionário que contempla a questão: Em que se baseia o comprometimento da sua organização com as organizações da lista, com as quais são estabelecidas relações? As respostas são de natureza nominal, em que os números não indicam valor que expresse ordem: 1 (não há comprometimento); 2 (obrigações); 3 (acordo); 4 (conveniência); 5 (espontâneo).

Conforme foram expostos os apontamentos dos atores quanto a base de comprometimento destes entre si, alerta-se para uma das limitações das respostas de alguns, quando assumem para todas ou para a maioria das relações a mesma base do comprometimento. Na Tabela 4 se explicita de maneira mais detalhada o perfil das respostas quanto à base de comprometimento entre os atores do campo organizacional. O detalhamento é distribuído valorizando as relações intra e intergrupos em percentuais.

\section{Tabela 4: Base de Comprometimento}

\begin{tabular}{|l|c|c|c|c|c|c|c|}
\hline & $\begin{array}{c}\text { Total } \\
\text { das } \\
\text { relações }\end{array}$ & Centro & $\begin{array}{c}\text { Centro x } \\
\text { Total }\end{array}$ & Intermediário & $\begin{array}{c}\text { Interm. } \\
\mathbf{x} \text { total }\end{array}$ & Periferia & $\begin{array}{c}\text { Periferia } \\
\mathbf{x} \text { total }\end{array}$ \\
\hline $\begin{array}{l}\text { Sem } \\
\text { comprom. }\end{array}$ & 21 & 6 & 15 & 22 & 23 & 43 & 23 \\
\hline Obrigações & 16 & 16 & 7 & 17 & 21 & 0 & 27 \\
\hline Acordo & 26 & 35 & 38 & 19 & 19 & 0 & 23 \\
\hline Conveniência & 17 & 19 & 21 & 19 & 17 & 29 & 7 \\
\hline Espontâneo & 21 & 23 & 20 & 23 & 21 & 29 & 20 \\
\hline
\end{tabular}

Fonte: Dados Primários

A afirmação dos atores no sentido de manifestar a inexistência de compromissos nas relações pode ser indicador de fraqueza entre as relações. A periferia é um exemplo claro de grupo que associa níveis baixos de densidade, freqüência, coesão e intensidade. O comportamento do grupo como um todo, bem como o intermediário e periférico se igualam quanto às bases de comprometimento, no que tange à resposta minha organização não se compromete com. Indicando que entre $21 \%$ e $23 \%$ das relações, não existe compromisso entre os atores. Esses números expressam a carência de ações estratégicas que estejam voltadas às relações estabelecidas entre os atores.

O comprometimento baseado em obrigações, parece apresentar poucas variações significativas, sendo base de compromisso para aproximadamente $16 \%$ 
das relações no interior de todo o campo organizacional, nas relações entre os atores do centro e intermediário. Os percentuais indicam a existência de hierarquia no interior do campo, marcada por relações apoiadas em obrigações predispostas nas relações de poder, confirmando a unilateralidade crescente à medida que as relações se dão em níveis mais distantes do centro. Em se tratando de relações que tenham como base de comprometimento o acordo bilateral tem sido apontado em $26 \%$ das relações. Geralmente são acordos previstos em contratos de fornecimento de produtos ou prestação de serviços. Das relações do campo organizacional que têm compromisso fundado em acordos, a organização focal detêm a maioria. Demonstra-se a baixa reciprocidade entre as bases de comprometimento, da organização focal e os atores do campo organizacional. Enquanto ela aponta que $90 \%$ das suas relações são fundamentadas em acordos, apenas $51 \%$ dos demais atores do campo afirmam ter comprometimento com esta, fundados em acordos. Essa distância em termos de respostas manifesta relações de unilateralidade com a organização focal. Quanto ao comprometimento por conveniência e espontâneo, parecem estar homogeneamente distribuídos em todo o campo organizacional variando entre $17 \%$ e $23 \%$, à exceção do grupo periférico que aparece com 29\%. O grupo intermediário apresenta diversidade no que fundamenta o comprometimento entre os atores tanto intra/inter grupo.

A variável base predominante dos relacionamentos consiste nas condições que dão sustentação às relações entre os atores, podendo variar entre as relações formais e a amizade (Fligstein, 1991). Para este estudo são consideradas cinco condições dispostas numa matriz com valores nominais, para a questão: Como você qualifica a base predominante dos relacionamentos mantidos entre a sua organização e as organizações da lista com as quais se relaciona? Tendo como possibilidades: 1 (amizade); 2 (parentesco); 3 (status); 4 (políticas); 5 (econômicas). Os resultados estão concentrados na base econômica, 83\%, expressa pelos acordos de prestação de serviços ou fornecimento de produtos entre os atores.

As atividades realizadas em conjunto pelos atores consistem em ações que os atores do campo procuram realizar aliados. A operacionalização desta variável acontece a partir da questão: Que tipo de atividade é realizada em conjunto entre a sua organização e as organizações da lista com as quais tem relação? As respostas consistem em 5 possibilidades: 1 (pressão política); 2 (troca de informações); 3 (redução de custos); 4 (atividades sociais); 5 (entrada em novos mercados). Atores além de terem a possibilidade de mais de uma escolha, também atribuem valor para as ações conjuntas: (1) pouco relevante; (2) relevante; (3) muito relevante. A partir da resposta a esta questão, foram construídas cinco matrizes, a partir das quais pode-se constatar a baixa incidência de atividades realizadas em conjunto no campo organizacional. 
Do total das relações ou nós entre os atores do campo, apenas $3 \%$ são aproveitadas em termos de ação conjunta por pressão política - uma densidade de $(0,01)$. É clara a falta de reciprocidade entre estas relações por parte das organizações do centro, em especial da organização focal e da prefeitura. Apenas $14 \%$ do total das relações entre os atores agrega ações conjuntas com a intenção de reduzir custos. Esses números confirmam a baixa utilização da cooperação para fins estratégicos em busca da competitividade, principalmente no que tange a preços, principal fator de competitividade apontado para as organizações do campo organizacional. A organização focal é a que mais movimenta ações em torno de tentativas que busquem reduzir custos para a sua atividade, alegando ter ação conjunta com 30 atores do campo para tal fim, considerando estas relações relevantes. Porém a avaliação da contrapartida não apresenta reciprocidade. Apenas 7 atores afirmam ter ação conjunta com a organização focal com a finalidade de reduzir custos, o que indica baixa reciprocidade entre os atores e a organização focal, a qual parece estabelecer exigência por custos baixos. Dentre o total de relações estabelecidas entre os atores do campo organizacional, 11\% constituem-se em ações conjuntas com fins sociais, referindo-se a ações beneficentes do município, bem como a eventos comemorativos, promovidos pela organização focal. Apenas $4 \%$ do total das relações entre os atores são convertidas em ações conjuntas voltadas para estratégias de entrada em novos mercados, estando a maioria concentrada no grupo intermediário. Nota-se que muitas destas interações acontecem em parceria com a organização focal mediante estratégias de expansão dessa pela instalação de unidades produtivas em outras localidades do país, mantendo a estrutura de fornecimento e prestação de serviços. Diversos atores ambicionam este tipo de relação com a organização focal, pela verificação do rápido crescimento econômico. A falta de cooperação confirmada aqui, revela que atores agem de maneira isolada, embora compartilhem estruturas institucionais.

Há que se admitir a importância de alguns atores na delimitação e influência na construção das estruturas institucionais do campo organizacional. O estudo da centralidade oferece instrumentos para inferências que dêem respostas aos limites da influência dos atores centrais no conteúdo das estruturas institucionais, bem como na evidência dos isomorfismos.

Knoke (1994) apontou que a maioria das redes interorganizacionais contém um núcleo central de organizações que dominam o fluxo de recursos. Para Knoke e Laumann (1982), a combinação da centralidade da rede e as relações de troca de recursos controlados definem a posição de uma organização na hierarquia da rede, sendo que cada posição na rede pode, de acordo com Pattison (1994), determinar diferenças quanto às informações a serem recebidas e por conseqüência, diferentes formas de construção do conhecimento seriam desenvolvidas. Pode-se afirmar que uma das contribuições da análise de redes 
para as inferências sobre as estruturas institucionais normativas e cognitivas consiste nos cálculos acerca da densidade e centralidade das relações. O campo organizacional em estudo aponta um grupo central extremamente denso $(1,0)$, seguido do grupo intermediário, que, além de ser formado pela maioria dos atores da rede, apresenta um nível de densidade que permite o fluxo de trocas, possibilitando movimentos de definição e redefinição de padrões de ação. Partindo da idéia de que a densidade do campo descreve os níveis de coesão, e a centralização descreve a medida em que esta coesão está organizada em torno de atores focais (Scott, 2000), pode-se afirmar que o campo organizacional em estudo apresenta considerável grau de centralização em torno da organização focal. De acordo com Stevenson e Greenberg (2000), alguns atores estão em posição de constranger e outros em condições constrangidas, são estas posições que ocasionam as desigualdades das relações de poder, o que parece determinístico, pois atores centrais podem ter suas ações mais limitadas e constrangidas do que os atores periféricos, reagindo mais do que criando novas situações (Degenne \& Forsé, 1999; Knoke, 1994; Stevenson \& Greenberg, 2000).

Alguns autores, como Borgatti e Everett (1992) e Marsden e Friedkin (1994), se reportam às práticas semelhantes enquanto processo de contágio, a imitação de comportamentos de atores. Duas perspectivas são apontadas para medir a proximidade e a influência entre os atores - a coesão e a equivalência estrutural. A proximidade entre os atores também levantada por Mizruchi e Galaskiewicz (1994) e Lomi e Grandi (1999), com o conceito de cliques, estando relacionada à freqüência do contatos (Walker, Wasserman \& Wellman, 1994). As entrevistas com os atores do campo organizacional têm demonstrado que os contatos acontecem de maneira dividida entre as duas formas, pessoal e por telefone, sendo este o mecanismo mais utilizado entre os atores. Para Degenne e Forsé (1999), um clique consiste num grupo informal de atores que compartilham sentimento de pertença, algum grau de intimidade e reconhecidas normas de comportamento. Portanto, a identificação de cliques, ou de grupos estruturalmente equivalentes e coesos pode contribuir para o esclarecimento de quais grupos de atores participariam na definição e redefinição das estruturas institucionais. É válido salientar que um clique não carece constituir um grupo, mas participar conjuntamente em determinadas atividades, mais ou menos distribuídas de acordo com os papéis sociais (Degenne \& Forsé, 1999). Estas afirmativas contribuem para a explanação acerca das estruturas normativas, as quais contemplam os valores e papéis reconhecidos no campo organizacional.

Um clique, para Borgatti, Everett e Freeman (2002), consiste num subgráfico completo no seu nível máximo. O cálculo por meio do UCINET fornece o número de vezes que cada par de atores está no mesmo clique. A partir daí são construídas hierarquias de agrupamentos - hierarchical clustering. Esta rotina do programa 
também executa uma operação dual mediante o exame do número de atores que um par de cliques tem em comum. Na seqüência são testados cálculos com cliques compostos por 3, número mínimo para o conceito de clique, com 15, 19 e 20 atores. A intenção é verificar equivalência estrutural do campo organizacional, partindo da idéia de que grupos que são estruturalmente semelhantes tendem a compartilhar conteúdos comuns nas interações.

O campo organizacional é composto por 103 cliques, formados por 3 atores. $\mathrm{O}$ estudo aponta a organização focal e a distribuidora de energia elétrica como as organizações que participam de todos os cliques, seguidas pela prefeitura, com participação em 99 cliques, pela organização responsável pelo saneamento (79), a produtora de embalagens plásticas aparece em 59 cliques; a universidade participa em 37 cliques. Estes números confirmam: 1) centralidade da organização focal demonstrada na hierarquia da estruturação; 2) o contrário acontece com a universidade local, que aponta um número inferior ao de várias organizações que estão situadas no nível intermediário do campo organizacional, corroborando com as afirmações quanto à baixa expressão desta na construção das estruturas normativas, bem como no isomorfismo normativo do campo organizacional; 3) a organização produtora de embalagens plásticas apresenta participação expressiva na estruturação, o que oferece suporte às constatações quanto ao papel desta nos processos de isomorfismo mimético no campo organizacional; 4) o fato de alguns atores pertencerem ao grupo do centro não implica necessariamente que estabelecem relações de poder com os outros atores.

Na sequiência, estruturando o campo organizacional com cliques compostos por 15 atores, o resultado no número de cliques diminui em proporções inversas, ou seja, a nova configuração estabelece 15 cliques. A hierarquia para esta disposição reforça ainda mais a estruturação do campo com cliques formados por 3 atores. Estas constatações não corroboram com as afirmações de que a universidade se constitui em focos para o desencadeamento de estruturas normativas (DiMaggio \& Powell, 1983). O número máximo de atores para a formação de um clique é de 19 atores, que constituem em apenas 1 clique. As organizações que constituem este clique pertencem ao grupo do centro (exceto uma instituição financeira) do campo organizacional, bem como das principais organizações do grupo intermediário, expostas em explanações anteriores. Esta estruturação, associada ao conteúdo das entrevistas oferece forte indício de quais organizações do campo organizacional são definitivamente mais ativas. A partir daí pode-se visualizar com clareza as organizações que mais interagem no campo organizacional: são 19 organizações que estão locadas em posições que permitem o fluxo de informações bem como de conhecimento. Pode-se afirmar que de maneira geral são estas organizações que influenciam e contribuem ativamente na construção e disseminação, definição e redefinição das estruturas institucionais 
regulativas, normativas e cognitivas, bem como influenciam no estabelecimento de padrões de ação semelhantes, desencadeando processos de isomorfismo coercitivo, normativo e mimético, constatação feita a partir das análises de conteúdo e de discurso das entrevistas semi-estruturadas com pelo menos um ator chave de cada organização.

Para oferecer suporte e confirmação aos resultados obtidos a partir do exposto, utiliza-se o cálculo do programa UCINET , que divide o campo organizacional em facções. Os resultados da distribuição dos atores em 3 facções confirmam a condição de alguns atores no campo organizacional. A demonstração a seguir configura a densidade entre as e dentro de cada uma das 3 facções.

\section{Tabela 5: Densidade entre Facções}

$$
\begin{array}{cccc} 
& 1 & 2 & 3 \\
--- & --- & --- \\
1 & 0.10 & 0.31 & 0.00 \\
2 & 0.25 & 0.71 & 0.24 \\
3 & 0.00 & 0.34 & 0.45
\end{array}
$$

Dividido o campo organizacional em 3 facções, confirmam-se as posições dos atores pouco ativos, bem como o nível de densidade dos atores que mais se relacionam entre si no campo $(0,71)$. Reconhecida a densidade do campo organizacional como um todo e de forma classificada torna-se interessante verificar se as ligações são fortes ou fracas. O UCINET oferece mecanismos para o cálculo das relações ausentes, fracas e fortes. O cálculo é coerente com a afirmação de Granovetter (1982), de que a força das ligações se resume à frequiência dos contatos que isto engendra, e que se for aceito que todas as ligações em um clique (rede densa) são fortes, logo as ligações entre os cliques serão por definição na maioria fracas.

Tabela 6: Distribution of Ties

\begin{tabular}{rll}
1 & \multicolumn{1}{l}{2} \\
Freq & \multicolumn{1}{c}{ Pct $(\%)$} \\
----- & ----- \\
1 Absent & 232.000 & 28.571 \\
2 Weak & 580.000 & 71.429 \\
3 Strong & 0.000 & 0.000
\end{tabular}


Os resultados apontam que mesmo possuindo uma densidade de 0,71 as ligações não são fortes, diferente é o resultado da análise feita apenas com o grupo central do campo organizacional.

\section{Tabela 7: Distribution of Ties}

$\begin{array}{lcc} & 1 & 2 \\ & \text { Fre } & \text { Pct } \\ & --- & --- \\ 1 \text { Absent } & 0 & 0 \\ 2 \text { Weak } & 0 & 0 \\ 3 \text { Strong } & 15 & 100\end{array}$

Pode-se afirmar que apenas os atores do centro possuem uma estrutura de relações que além de densas $(1,0)$ são fortes. Estes números corroboram com as inferências a respeito do baixo nível de cooperação entre os atores expressos nas entrevistas e no resultado da questão que infere sobre as atividades realizadas em conjunto pelos atores. Porém, conforme foi apresentado, Granovetter (1982) e Burt (1995) descreveram o mesmo fenômeno - o primeiro retrata a força das relações fracas e o segundo do conceito de structural holes - ambos apontam vantagens para as relações consideradas fracas ou das lacunas na rede, principalmente no que tange ao aproveitamento de idéias de fora do campo organizacional e da abertura para inovações, ou ainda em processos de competição, quando relações fracas demonstram força na medida em que consistem em pontes para outros grupos de atores (vide Machado-da-Silva \& Coser, 2004). Pode-se inferir que as relações entre os atores do campo organizacional não necessitam ser consideradas fortes para que aconteça a pulverização de valores, símbolos e interpretações, bem como o desencadeamento de isomorfismos.

Identificado o grupo de atores do campo organizacional com o auxílio dos cálculos estruturais, pode-se afirmar que a sua densidade é adequada $(0,70)$ para que as estruturas institucionais sejam reproduzidas e reconstruídas em meio ao conflito, cooperação e competição. Cabe então, diante da estruturação das relações do campo organizacional, analisar como os processos de isomorfismo e as estruturas institucionais, descobertos também a partir de análises de cunho qualitativo.

Tais inferências estão assentadas na análise discursiva e de conteúdo, proposta por Spink (1999), complementadas pela utilização do software SPHINX para sistematização do conteúdo dos textos das entrevistas semi-estruturadas e pela especificação das categorias de análise mediante planilhas do Excel. Os dados secundários também compõem as análises em que são investigados periódicos, jornais, contratos, leis entre outros registros. 
Os esforços dispensados no referido estudo também buscam pôr em relevo outras formas e conteúdos de troca, ou seja, apontar para as trocas intersubjetivas, o que é compartilhado e construído ou transformado a partir das relações estabelecidas no campo organizacional e no município. O foco do estudo está nas estruturas institucionais presentes nas relações do campo, classificadas em regulativas, normativas e cognitivas, considerando o espaço de pesquisa como dotado de historicidade e movimentos de definição e redefinição recursiva de estruturas que tanto habilitam quanto constrangem as ações dos atores.

As condições que envolvem a organização focal do estudo são bastante especiais no sentido de que ela é para os atores do campo organizacional e para o município praticamente uma instituição. A compreensão acerca desta transcende a visão de uma organização com fins de produção; esta dimensão é subordinada a questões históricas, políticas e sociais, onde as trajetórias do município e da Alpha se confundem.

A dependência no campo organizacional posta em termos de sobrevivência. Trabalhar às custas das relações com a Alpha parece resultar numa relação de culto e adoração à organização mãe provedora de tudo para todos. Os entrevistados se situam na condição de dependentes e também se reconhecem a partir da constatação intrigante de que todos estabelecem o mesmo vínculo com a Alpha. Essa relação entre a organização e os outros atores, bem como as ações da organização são exteriores e objetivas, reconhecidas e compartilhadas nas interações servindo de base para a construção das interpretações de cada ator envolvido, daí a validade da abordagem institucional, na medida em que sua tradição fenomenológica funda-se nas construções intersubjetivas (Leuenberger \& Pinch, 2000).

Admitir a existência de estruturas institucionais dentro do campo organizacional em análise requer um esforço no sentido de compreender quais estruturas imperam e de onde se originam. O que se propõe então é a análise a partir da classificação das três estruturas - regulativa, normativa e cognitiva - que também são inseparáveis dos três mecanismos de isomorfismo - coercitivo, normativo e mimético. Destaca-se que essa classificação é quase impossível em termos empíricos, servindo portanto, como recurso teórico capaz de denunciar algumas características marcantes, que permitem denominá-las separadamente (Mizruchi \& Fein, 1999).

Constatou-se que as principais determinações reconhecidas pelos atores como regras consistem em regimentos necessários ao desempenho das atividades que compõem a natureza de cada organização. São estruturas regulativas advindas de órgãos governamentais, fundadas na legislação, que asseguram ao Estado o 
direito de fiscalizar e punir. Estas leis conferem confiança nas relações entre os atores. Ou seja, atores se beneficiam das regras impostas à sua atividade como forma de oferecer segurança e credibilidade. A influência da Alpha neste caso, incide principalmente no sentido de restringir contratos com terceiros, quando estes não cumprirem com todas as obrigações legais trabalhistas, fiscais e ambientais, entre outros. Dessa forma, o Estado desencadeia algumas estruturas regulativas, na forma de leis, regimentos e fiscalizações que são garantidas no campo organizacional via outra estrutura regulativa advinda da organização focal, por mecanismos bastante claros de punição, expressos na ruptura de contratos ou interrupção dos pagamentos pelos serviços prestados até regularização de tais condições legais. A organização focal neste sentido também se beneficia deste procedimento perante o campo organizacional e perante o Estado, tendo em vista a não obrigatoriedade desse tipo de procedimento no setor privado. As entrevistas com atores da organização focal, denunciam o fato de que as regras não são para a Alpha nas relações com as outras organizações; é ela quem as determina. Essa relação é justificada a partir do discurso em torno da ordem do mercado, da competição e da globalização.

Então, negociar, influenciar, resistir, manipular as regras ou exigências não compõem o predicado da maioria dos atores dependentes da organização focal em lugar disso a aquiescência para a maioria e a tentativa de diminuição dos níveis de dependência via pulverização da carteira de clientes, para tanto, os níveis de referência ambiental avançam as fronteiras locais.

O componente normativo atribui "ênfase sobre as estruturas normativas que introduzem uma dimensão prescritiva, avaliativa e obrigatória dentro da vida social" (Scott, 1995, p. 37). Os dirigentes do campo organizacional são um grupo crítico no exame de valores, porque eles controlam o desenho e o funcionamento das organizações. As estruturas podem refletir os valores dos dirigentes e podem mudar também de acordo com a legitimação de novos valores (Hinings, Thibault, Slack \& Kikulis, 1996).

A perspectiva das estruturas normativas trata do reconhecimento por parte dos atores com relação aos papéis que executam no interior do campo, e dos valores que compõem estes papéis, bem como da percepção dos atores do campo com relação aos papéis desempenhados pelos demais atores. Foram identificados valores nas entrevistas e coleta de dados secundários: iniciando com o atendimento ao cliente, qualidade, profissionalismo, ética, acompanhamento dos avanços tecnológicos, moral e retornos financeiros. A partir daí pode-se fazer uma conexão com os valores intensamente pregados pela organização focal, obedecendo à ordem: valorização do cliente, desenvolvimento individual, responsabilidade profissional, ética nos relacionamentos, agilidade nas mudanças, trabalho em equipe, 
satisfação do consumidor e gestão eficaz. Nota-se que os valores presentes no campo que convergem com a organização focal consistem naqueles acerca da valorização do cliente, do profissionalismo (advindos da transição da organização focal de familiar para profissional, a partir de 1994), da ética (compreendida pelos atores como sinônimo de moral) e da gestão eficaz dos recursos (manifesta nas tecnologias de gestão apresentadas pela organização focal por meio de palestras, comunicação constante, encontros entre outros). A busca pelo acompanhamento tecnológico tem sido um dos valores mais apresentados por aquelas organizações do campo que trabalham com a organização focal, mas que têm como níveis de referência ambiental nacional e internacional.

Outro ponto associado às estruturas normativas diz respeito aos papéis reconhecidos pelos atores sobre si e sobre o outro. Quando atores questionados sobre os seus papéis, a resposta culmina especialmente no posicionamento com relação à organização focal, ou seja, o fornecimento de materiais ou serviços necessários à cadeia produtiva agroindustrial instalada. Quanto à categorização das profissões mais valorizadas nas organizações pelos dirigentes parece não ter muita sofisticação. A valorização das profissões está estritamente associada à atividade operacional das organizações, ou seja, a técnica é bastante valorizada nas organizações.

É importante considerar na perspectiva das estruturas normativas e no isomorfismo normativo, o papel desempenhado pelas instituições de ensino, neste caso as universidades. No referido campo a universidade não consiste em agente determinante das estruturas normativas. As relações com a universidade local se concretizam mais a partir da noção de que ela é uma grande compradora de produtos e serviços necessários à sua infra-estrutura física. A referida universidade tem consciência desta distância, mas demonstra dar suporte, reprodução e manutenção ao sistema de produção em torno do complexo agroindustrial, justificado também no fato de que a organização focal emprega mais da metade dos alunos da instituição. O isomorfismo normativo é evidenciado então, no referido campo organizacional, a partir de encontros, cursos e palestras promovidos pela organização focal, principalmente pela disseminação de tecnologias de gestão mediante cursos, treinamentos, palestras difundidos entre terceiros, fornecedores e prestadores de serviço. Outro fator importante está atrelado ao fato de que entre as 40 organizações do campo, 10 foram fundadas a partir do desligamento de funcionários da organização focal com a finalidade da abertura de um negócio que visasse produzir serviços ou produtos para a mesma. Estes dirigentes trabalharam na Alpha em cargos que vão desde analista à diretoria. A saída, na maioria dos casos foi decorrente de novas estruturações da empresa, ou negociação entre o futuro empreendedor e a sua idéia, com a Alpha. 
AAlpha, em face das novas exigências da globalização, dos apelos da qualidade, dos novos conceitos de gestão e desenvolvimento humano, iniciou um movimento que tinha e ainda tem por objetivo a formação dos funcionários, o qual foi estendido a todas os jovens e adultos do município. Desde 1996, início dos trabalhos, a Alpha, via sistema de sanções, está concretizando um dos seus objetivos: o máximo possível de funcionários em formação escolar constante, o que ocasionou na presença de funcionários de outras organizações do campo, desempregados entre outros. A movimentação inicial foi guiada por pressões regulativas, passando a ser instituída normativamente pelo vislumbre de novos valores, gerados pela constatação de novas demandas sociais e econômicas.

Os predicados de natureza normativa da organização focal têm sido no sentido de orientar as decisões da maioria dos atores do campo e do espaço social. É aquela que incentiva, motiva, conduz, organiza, direciona de forma bastante natural e legítima. Diante do exposto questiona-se: até que ponto a organização focal pretende ser o que é? Até que ponto é vantagem para ela e para o município se estabelecer uma relação de tanta dependência? São questionamentos feitos aos dirigentes da organização focal. As respostas parecem ter indicado um rever conceitos, um repensar as ações até então praticadas. É um querer e não querer, pois a relação construída pela organização focal com o município se constitui em vantagem à medida que a maioria dos atores compartilha dos valores da organização, os aceita e legitima. $O$ fato de a organização focal estar na vitrine envolve responsabilidades das quais não se faz questão de assumir. A sociedade espera e solicita ações coerentes, deseja que as coisas permaneçam equilibradas.

As explanações sobre as estruturas cognitivas a partir da identificação das categorias de interpretação do ambiente compartilhadas entre os atores do campo. As categorias de interpretação do ambiente parecem nortear ações estratégicas um tanto diversificadas, pois o isomorfismo mimético permite o exame dos efeitos do ambiente sem a necessidade de focar na coerção exercida por organizações poderosas (Mizruchi \& Fein 1999). Principia-se pela interpretação do ambiente pelos atores do campo organizacional e atesta-se que as percepções acerca do ambiente estão bastante associadas à competição, dentro e fora do campo organizacional. $\mathrm{O}$ ambiente de referência para muitos atores passa a ser nacional e internacional, ou seja, atores percebem as organizações que já avançaram para o mercado internacional também como as que possuem mais sucesso dentro do campo organizacional.

Assinala-se que muitos atores do campo prestam atenção nas outras organizações do campo, em especial à organização focal. Mas quando se trata de assimilar e aplicar estratégias, as atenções são voltadas para organizações de fora do campo organizacional, principalmente as grandes, do mesmo setor. Estes 
atores trazem o novo e arriscam em meio a incertezas, pagam caro por isso e, mais tarde são objetos de emulação para os outros atores do campo organizacional. Para D’Aunno, Succi e Alexander (2000), organizações também podem imitar modelos de ação que são divergentes dentro de um campo organizacional. Porém é indispensável lembrar que o objeto de imitação vindo de fora do campo assume uma característica mais pontual e também mais técnica sendo muito mais fruto da vontade de inovação do que do receio das incertezas provocadas pelo ambiente.

Os atores foram questionados sobre quais organizações teriam mais prestígio no campo organizacional e no município, bem como os motivos que os fazem eleger tais organizações. O próximo passo foi verificar se estas organizações procuram se espelhar ou prestar atenção sobre o que estas fazem, para tentar imitar suas práticas. As respostas configuram o seguinte: a maioria (com exceção de 4 atores) elegeram a organização focal como a que tem mais prestígio no campo organizacional. As razões para tal escolha estão associadas ao tamanho da organização. Os atores prestam atenção no que ela faz, procuram estar próximos de seus valores. O isomorfismo mimético provocado pelo prestígio não parece ser decisivo, pois o tamanho aqui para muitos é fator limitante, ou seja, os atores se reconhecem ínfimos quando comparados à organização focal, que parece ter para o campo aura de inevitabilidade (Deephouse, 1996, p. 1029). Padrões e arranjos foram propagados por todo o campo pela organização focal a partir de pressões normativas e regulativas. As relações de poder, associadas ao tamanho da organização focal e sua relação de dependência com os outros atores, é o que mais provoca nestes a incerteza de sobrevivência, no caso de não aderência a tais conceitos e práticas.

Quanto à questão em torno da organização que seria percebida como a que tem mais sucesso, as respostas ficaram divididas entre a Alpha e uma organização do setor de embalagens plásticas; pelo tamanho da Alpha e pela trajetória da última. O sucesso da Alpha estaria associado então à sua expansão, a sua capacidade de se manter grande, enquanto que a segunda surpreende pelo imaginário de sucesso, o que corrobora com Hannan e Freeman (1989) e Haveman (1993) quando apontam que muitas organizações podem imitar outras organizações da população que são semelhantes em termos de estrutura, estratégia, recursos e imperativos, mas são as organizações que têm sucesso objeto de comparação e imitação, proposição evidenciada no campo organizacional em estudo.Os atores do campo também podem, além de se identificar, tentar se assemelhar a padrões e procedimentos que caminhem em direção a mudanças dos padrões mais antigos. Não significa desintitucionalizar estruturas, mas institucionalizar outras formas estruturais organizacionais no campo, via legitimação de novos valores e conceitos. De acordo com Oster (1990), "estratégias de sucesso são os alvos principais de imitação, e a imitação tende a igualar retornos" (p. 91). 
Desperta-se então para a importância dos dirigentes na construção das estruturas cognitivas do campo organizacional. Há que se admitir o papel dos dirigentes na definição dos valores e conceitos difundidos. O ponto chave reside no fato de estes serem compreendidos como capacitados para lidar com crise, com incertezas e ambientes turbulentos. As categorizações de interpretação destes dirigentes tende a criar uma visão de mundo particular de comportamento organizacional apropriado dentro do campo organizacional (Galaskiewicz \& Wasserman, 1989). A sociedade desta forma passa a ser uma comunidade de seguidores de regras com distintas relações socioculturais, compreensões intersubjetivas fundadas no compartilhamento de códigos de significado e formas de raciocínio, bem como um senso de pertença. As identidades e regras são constitutivas bem como moldadas pela experiência e interação social. (vide Coser \& Machado-da-Silva, 2004)

Cabe nesta análise configurar as relações entre o setor público, definido para o estudo enquanto órgãos executivo e legislativo do município. O objetivo é evidenciar os padrões de relação entre estes atores ao longo do tempo. Foram entrevistados para tal, três membros do poder legislativo do município, estando um destes no terceiro mandato. Além das entrevistas foram analisadas leis a partir de 1997 que previam as atividades econômicas, culturais e sociais do município, principalmente as associadas à organização focal, materiais de divulgação do município, lei orgânica municipal, jornais locais e jornal interno da Alpha.

Após várias lutas políticas, finalmente o município que reunia duas vilas foi emancipado, em 1943, quando a Alpha já completava uma década. Impossível não associar as duas histórias, a situação parece conter apenas uma história. Nos primórdios do município a organização focal participou, exerceu influência e poder sobre as decisões econômicas e políticas mais importantes. As entrevistas e os documentos analisados indicam que a força e a coerção não têm sido a marca da organização focal atualmente. Porém os entrevistados lembram do período em que a organização focal era familiar. Personalidades impunham freqüentemente a sua vontade política via exercício pleno de poder. O conteúdo destas exigências limitava por exemplo, a entrada de novas empresas no município, conforme foi anunciado por vários atores da rede. Outra força bastante presente se concretizava no plano político partidário, no qual a Alpha, via dirigentes, principalmente proprietários, praticamente determinavam quem iria assumir o governo municipal. O poder aí não era velado, nem se fazia questão de ser, e o município se encontrava sob um regime nefasto, à base de circunstâncias econômicas.

Há indícios de que a transição da era familiar: que se caracterizava como um império no município, para a era profissional trouxe mudanças sensíveis no delineamento político do município, embora desde os primórdios da administração 
pública as relações entre a organização focal e o governo municipal, vão além das trocas entre arrecadação e obras públicas. Elas também acontecem no plano normativo, objetivadas nas sugestões e idéias sobre como conduzir o município e no acolhimento das solicitações da organização focal. Os resultados da pesquisa sobre os registros do legislativo do município provam que organização focal possui suporte e poder político sobre as decisões a ponto de serem alterados percursos legais para as ações públicas. E ninguém quer se indispor com a Alpha, dado aos custos impelidos nessa ação. A idéia de desenvolvimento local então, é assentada no discurso de crescimento e na continuidade da organização focal. Outra característica marcante do governo municipal é a atribuição de importância diretamente proporcional ao que se arrecada.

A competição aqui também é desencadeada para a obtenção de legitimidade, para a institucionalização de alguns padrões estruturais mais favoráveis entre outros. É importante anunciar que as análises em torno da competição precisam contemplar a importância das estruturas institucionais e dos isomorfismos, em especial o isomorfismo mimético. Este cuidado se deve ao fato de que muitos atores não competem entre si dentro do campo, mas compartilham as mesmas identidades enquanto unidades de apoio, periféricas ou centrais que interagem entre si e principalmente com a organização focal.

As percepções quanto à competição dentro do campo também variam de acordo com os seus níveis de referência, que vão do local ao internacional. O ambiente de competição no campo organizacional é mais marcado pelo conflito do que pela cooperação, sendo constituído basicamente pela batalha de preços, alimentada pelas licitações tanto no setor público, como pelos requisitos adotados pela organização focal. A relação entre os atores que competem mais enfaticamente com organizações nacionais e internacionais parece ser dotada de refinamentos interpretativos, apresentando sinais de cooperação, de alianças estratégicas, de parcerias. Para esses atores a tecnologia, qualidade, inovação, excelência, eficiência e preço são partes constitutivas do ambiente técnico. Desta forma trabalha-se com a interpretação de ambientes de referência mais amplos dentro de um ambiente menor, onde se pretende acrescentar valores e conceitos mais abrangentes.

Uma outra diferença entre estes dois grupos reside no encaminhamento das negociações com a organização focal. À medida que os níveis de referência vão avançando as fronteiras do campo organizacional, crescem também as possibilidades de negociação com a organização focal, pois estão mais preparados para lidar com as dificuldades da dependência que têm com organização focal, propiciando relações bilaterais, diferente das relações entre a Alpha e os demais atores com referência local envolvem muito mais dependência e unilateralidade. 
É essa diversidade de interesses e interpretações da realidade entre outros que atribui forma a fenômenos pouco estáveis e previsíveis, como o conflito entre os atores, em face das ações do campo organizacional.

Parte-se da idéia de que os conflitos são desencadeados pela divergência tanto de interesses como da interpretação da realidade entre os atores, podendo atuar como força motriz para a mudança de padrões institucionalizados, via questionamentos acerca da sua validade dentro do campo organizacional. Encontrase dificuldade em perceber competição, conflito, relação de poder e estruturas regulativas, e isomorfismo coercitivo desassociados, daí a necessidade de encadeamento.

Alguns conflitos são originários da dissonância entre o discurso desenvolvimentista local e de práticas que pouco manifestam tais empreendimentos. As licitações são foco objetivo e concreto para conflitos entre vários atores do campo organizacional. Atores também denunciam o falso discurso em torno das relações de parceria que a organização focal estabelece com seus fornecedores, terceiros ou parceiros que têm uma relação de dependência bastante forte.

A competição interna é marcada principalmente pela disputa por espaço e mercado voltado para a organização focal, que acaba sendo favorecida pelos conflitos entre dois ou mais atores fornecedores, o que corrobora com Burt (1995, p. 30), que apontou para a importância de atores em contexto de conflito, os quais denomina de tertius, ou seja, o terceiro que se beneficia dos conflitos. A organização focal se beneficia do conflito gerado entre os seus fornecedores no sentido de poder impor padrões que lhe sejam adequados e que garantam o acesso aos recursos de que necessita dentro das condições desejadas. Os conflitos então servem também como força que impulsiona as discussões internas do campo, com vistas a novas construções institucionais. É partindo das relações de poder que se pode detectar quais frutos do conflito efetivamente perduram em função de determinados interesses.

As relações de poder consistem, para o referido estudo, nas relações de controle e dependência entre os atores, dos canais de comunicação, informações e recursos materiais e imateriais que são importantes dentro de um campo organizacional. Estas relações seriam reforçadas, mantidas ou reproduzidas a partir do esforço dos atores em determinar valores, crenças, regras e conceitos a serem compartilhados e legitimados no campo organizacional e que reforcem um modus operandi que dê continuidade ao poder conquistado. É reconhecida a capacidade dos atores de manipular, reinterpretar e contestar estes símbolos e práticas das instituições. A natureza institucional do poder no campo fornece oportunidades tanto para a sua reprodução quanto para a transformação. 
Foi unânime a resposta Alpha entre os atores do campo organizacional bem como de alguns atores do município, quando questionados sobre qual seria a organização mais poderosa do campo organizacional e do município, o que coaduna com as explanações de Luke (1999, p. 145), ao afirmar que "indivíduos e grupos estão emaranhados dentro de táticas e estratégias das mais complexas formas de poder, dos quais instituições, procedimentos, análises e técnicas livremente administram populações e cercanias em uma economia material e simbólica altamente politizada".

As relações de poder, no plano do discurso são caracterizadas pela intersubjetividade, nas relações entre os atores, bem como pelo controle de recursos alocativos e autoritários (Giddens, 1989).

Há causas estruturais e relacionais para a centralização do poder no campo. Alguns atores se dão conta disso, outros compreendem como uma espécie de influência, bastante natural, afinal de contas, o fator econômico legitima estas relações quando se admite que mais de $90 \%$ da economia do município é originada das suas atividades. DiMaggio e Powell (1991) afirmaram que "quanto maior a dependência de uma organização sobre outra, mais semelhante esta organização irá se tornar à outra em termos de estrutura e foco de comportamento [...] reconhece-se uma maior habilidade das organizações para resistir às demandas das organizações com as quais não se tem relação de dependência" (p. 74). A dependência de recursos também aparece como vetor para as relações de poder.

Se o poder é também relacional, se concretiza a partir do discurso, da intersubjetividade, da dependência, pode-se afirmar que o discurso, que dá sustentação a todas as imposições que a organização focal faz no campo das transações, é elaborado a partir das construções, das estruturas institucionais, que ao mesmo tempo que oferecem padrões de ação, são redefinidas nestas interações, que são também marcadas por relações de poder. $\mathrm{O}$ discurso em torno da competitividade, da globalização, da qualidade entre outros, sustenta as relações de poder num plano legítimo e posteriormente componente de estruturas institucionalizadas, o que permite que as relações de poder sejam percebidas como naturais. Considerando que as estruturas institucionais vão sendo definidas, construídas socialmente e recebendo altos níveis de influência da organização focal, marcadas por relações de poder coercitivas ou sutis, um modus operandi vai se acomodando no campo organizacional (vide Machado-da-Silva \& Coser, 2004b). Então, questões sobre o poder devem estar atreladas a análise de quais práticas, técnicas e procedimentos dão efeito (Townley, 1993, p. 520), sendo a inércia para determinadas ações do campo o resultado de um sistema de poder estável no campo organizacional (Fligstein, 1990). 
Há que se ressaltar a existência de relações de dependência que não implicam relações de poder; um exemplo claro disso diz respeito ao fornecimento de recursos vitais para as organizações, em especial a energia elétrica. Nenhum ator evidencia relação de poder da organização responsável por este recurso, nem mesmo as essenciais para as organizações - como as fornecedoras de água saneada e energia elétrica - se reconhecem dotadas de poder ou capacidade de estabelecer relações de poder com os outros atores.

Associado às relações de poder são desencadeadas também as relações de cooperação. Para Maillet (1996) as "redes são instaladas por atores que, individualmente, não têm os recursos necessários. Esta cooperação, geralmente de longo prazo, acrescenta criatividade e diminui os riscos e custos de um processo de inovação [...] os atores sabem o que é esperado da cooperação e retêm controle sobre os serviços retribuídos pelos parceiros" (p. 75). Estudos sugerem que a cooperação e competição entre organizações são embebidas em condições sociais ou contextos que estruturam as "regras de conduta" para comportamentos de cooperação e competição. São estas condições que influenciam como estes comportamentos são definidos, escolhidos e implementados. É essencial que os integrantes conheçam as obrigações formais e informais para sustentar uma relação de cooperação, como consequiência a probabilidade dessa relação falhar aumenta na medida em que se estabelecem negociações unilaterais. Essas assertivas contribuem à compreensão do fato de as organizações do campo organizacional admitirem realizarem pouco ou nenhuma atividade conjunta.

De acordo com Park e Ungson (2001), a proximidade cultural também constituise como fundamental no processos de cooperação. Aponta-se que alianças estratégicas auxiliam as organizações a "ganhar poder e acesso aos mercados, legitimidade institucional, e novas competências, bem como explorar competências específicas, além de reduzir incertezas ambientais" (Park \& Ungson, 2001, p. 51). Embora exista a proximidade cultural entre os atores, poucos despertaram para ações concretas com o objetivo de obter acesso aos mercados ou obter legitimidade.

Essa postura demonstra que as relações com atores que disputam pelos mesmos recursos são marcadas pela competição. Estratégias elaboradas de cooperação não são vislumbradas entre os atores que competem entre si. Pode-se afirmar que a falta de cooperação entre os atores pode ser atribuída a questões culturais bastante marcantes no campo organizacional. Apesar desse cenário pouco cooperativo, atores reconhecem o isolamento das ações, perdendo assim força e vantagem diante das incertezas, das dificuldades estruturais, das questões políticas do espaço social e das relações de força com a organização focal. 


\section{Considerações Finais}

Os resultados do referido estudo têm oferecido suporte para a confirmação de que análises organizacionais carecem da consideração de variáveis que transcendem os limites atrelados aos cálculos de eficiência, competência, produtividade entre tantos outros. Implica considerar, principalmente no estudo das relações interorganizacionais, aspectos históricos, sociais, políticos e econômicos. Inevitavelmente, as organizações não são tão racionais quanto pretendem de ser.

A partir da complementaridade das análises quantitativa, mediante a estruturação da rede do campo, e qualitativa mediante estudo do conteúdo das ligações do campo organizacional, composto pelas 40 organizações que integram um complexo agroindustrial, pode-se afirmar que a referida organização focal exerce alto grau de influência nas definições das estruturas institucionais regulativas e normativas, apresentando menor grau de influência sobre as estruturas cognitivas e o isomorfismo mimético. As relações de poder parecem contribuir na definição das estruturas institucionais na medida em que dão sustentação ao modus operandi vigente num processo bidirecional, sem relação causal definida.

A competição no campo de estudo divide-se em dois grupos: o de atores que dependem da organização focal e o grupo de atores que procura livrar-se da dependência mediante pulverização da carteira de clientes e conseqüente avanço para níveis de referência ambiental mais amplos. A interpretação do ambiente e os níveis de referência são diferentes para estes grupos. Enquanto o primeiro possui um nível de referência limitada ao plano local para as ações e estratégias, o segundo avança para os níveis nacional e internacional. Os conflitos também constituem as relações entre os atores do campo organizacional, sendo derivados da competição, da diversidade de interesses, da percepção de dissonância entre o discurso e a prática dos atores, bem como da possibilidade de diferentes interpretações acerca da realidade. A cooperação como ação estratégica não está presente nas estruturas cognitivas e normativas do campo organizacional.

A análise de redes possibilitou que as inferências acerca da estrutura das relações entre os atores do campo fossem consistentes, pois a partir do estudo das relações pode-se identificar os principais canais do campo organizacional, com o levantamento das organizações centrais, os atores mais importantes para o campo organizacional, a freqüência das relações, as atividades conjuntas entre outros resultados derivados das diversas equações dispostas no programa UCINET .

Uma das revelações de complementaridade entre a análise de redes e a 
abordagem institucional consistiu na enumeração das organizações do campo que atuam de forma mais ativa nos processos de definição, construção e redefinição de padrões que constituem as estruturas institucionais mediante a intersubjetividade.

À luz dos resultados do estudo propõem-se alguns questionamentos sobre a realidade apreciada. O primeiro diz respeito às vantagens obtidas pela organização focal mediante o tipo de relação estabelecida com o campo organizacional e com o espaço social. Os dados coletados oferecem suporte para se afirmar que a organização focal não consiste apenas num ente organizacional com fins produtivos e econômicos, a sua dimensão ultrapassa essas fronteiras na medida em que os atores a identificam enquanto principal agente da história, da sociedade, da política e da economia.

\section{Artigo recebido em 01.11.2004. Aprovado em 18.05.2005.}

\section{ReferênCIAS BibliográfiCAS}

Aiken, M., \&

Hage, J. (1968, December).

Organizational Interdependence and Intra-organizational Structure. American Sociological Review, 33(6), 912-930.

Amburgey, T. L., \&

Dacin, T. (1994, December).

As the left foot follows the right? The dynamics of strategic and structural change. Academy of Management Journal, 37(6), 1427-1452.

Berger, P. L., \&

Luckmann, T. (1985).

A construção social da realidade (19a ed.). Petrópolis: Vozes.

Berkowitz, S. D. (1982).

An introduction to structural analysis: the network approach to social researh. Canadá: Butterworth Co.
Borgatti, S. P., \&

Everett, M. G. (1992).

Notions of position in social network analysis. In P. V. Marsden (Ed.). Sociological Methodology. Oxford: Blakwell.

Borgatti, S. P., Everett, M. G., \&

Freeman, L. C. (2002).

Ucinet for Windows: Software for Social Network Analysis. Harvard: Analytic Technologies.

Bourdieu, P. (1986).

The forms of capital. In J. G. Richardson (Ed.). Handbook of theory and research for the sociology of education. New York: Greenwood.

Bourdieu, P., \&

Wacquant, L. J. D. (1992).

An invitation to reflexive sociology. Chicago: University of Chicago Press. 
Brint, S., \&

Karabel, J. (1991).

Institutional origins and transformations: the case of american community colleges. In W. Powell, \& P. J. DiMaggio (Eds.). The new institutionalism in organizational analysis. Chicago: University of Chicago Press.

Burt, R. S. (1983).

Applied network analysis: a methodological introduction. California: Sage Publications Inc.

Burt, R. S. (1995).

Structural holes: the social structure of competition. Massachusetts: Harvard University Press.

Casson, M., \&

Cox, H. (1999).

An economic model of inter-firm networks. In M. Ebers (Ed.). The formation of inter-organizational networks. New York: Oxford University Press.

Castells, M. (1996).

The information age: economy, society and culture. The rise of the network society (Vol 1). Malden, Mass: Blackwell.

\section{Coser, C., \&}

Machado-da-Silva, C. L. (2004). Isomorfismo na rede de relacionamentos do espaço social de Videira-SC. Anais do Encontro Nacional de Pós Graduação em Administração, Curitiba, PR, 28.

D’Aunno, T.,

Succi, M. \&

Alexander, J. A. (2000, December).

The role of institutional and market forces in divergent organizational change. Administrative Science Quarterly, 45 (4), 679-703.

Degenne, A., \&

Forsé, M. (1999).

Introducing Social Networks. London: Sage Publications.

Deephouse, D. L. (1996, August).

Does isomorphism legitimate? Academy of Management Journal, 39(4), 1024-1039.

Dimaggio, P. J. (1986).

Structural Analysis of Organizational Fields: a blockmodel approach. In B. M. Staw \& L. L. Cummings (Eds.). Research in Organizational Behavior, Vol. 8 (pp. 335-370). Greenwich, CT.: Jai Press.

DiMaggio, P. J., \&

Powell, W. W. (1991).

The iron cage revisited: institutional isomorphism and collective rationality in organizational fields. In W. Powell, \& P. J. DiMaggio. (Eds.). The new institutionalism in organizational analysis. Chicago: University of Chicago Press.

DiMaggio, P. J., \&

Powell, W. W. (1983, April).

The iron cage revisited: institutional isomorphism and collective rationality in organizational fields. American Sociological Review, 48(2), 147-160.

Dryzek, J. S. (1996).

The informal logic of institutional design. In R. E. Goodin (Ed.). The theory of institutional design. Cambrige: Cambrige University Press. 
Dubois, A., \&

Hakansson, H. (1999).

Relationships as activity links. In $\mathrm{M}$. Ebers (Ed.). The formation of interorganizational networks. New York: Oxford University Press.

Emirbayer, M., \&

Goodwin, J. (1994, May).

Network Analysis, culture and the problem of agency. American Journal of Sociology, 99(6), 1411-1454.

Evan, W. M. (1976).

Inter-organizational relations. Pensilvânia: University of Pensilvânia Press.

Fligstein, N. (1991).

The structural transformation of american insdustry: an institutional account of the causes of diversification in the large firms, 19191979. In W. Powell, \& P. J. DiMaggio (Eds.). The new institutionalism in organizational analysis. Chicago: University of Chicago Press.

Fligstein, N. (1990).

The transformation of corporate control. Cambrige: Harvard University Press.

Foucault, M. (1987)

Vigiar e Punir (23a ed.). Petrópolis: Vozes.

Galaskiewicz, J. (1979, June).

The structure of community organizational networks. Social Forces, 57(4), 1346-1364.

Galaskiewicz, J., \&

Wasserman, S. (1989, September). Mimetic processes within an interorganizational field: an empirical test. Administrative Science Quarterly, 34(3), 454-479.

Giddens, A. (1989).

A constituição da sociedade. São Paulo: Martins Fontes.

Granovetter, M. (1976, May).

Network samplin: some first steps. American Journal of Sociology, 81(6), 1287-1303.

Granovetter, M. (1982).

The strength of weak ties: a network theory revisited. In P. V. Marsden, \& N. Lin (Eds). Social structures and network analysis. Beverly Hills: Sage Publications.

Guler, I.,

Guillen, M. F., \&

Macpherson, J. M. (2002, June).

Global competition, institutions, and the diffusion of organizational practices: the international spread of ISO 9000 Quality Certificates. Administrative Science Quarterly, 47(2), 207-232.

Hagedoorn, J., \&

Duysters, G. (2002, July/August).

Learning in dynamic inter-firm networks: the efficacy of multiple contacts. Organization Studies, 23(4), 525-548.

Hannan, M. T., \&

Fremman, J. H. (1989).

Organizational Ecology. Cambrige: Harvard University Press.

Hatch, M., Jr. (1997).

Organization Theory: modern, simbolic, and postmodern perspectives. Oxford: Oxford University Press. 
Haveman, H. A. (1993, December).

Follow the leader: mimetic isomorphism and entry into new markets. Administrative Science Quarterly. 38(4), 593-627.

Hinings, C. R.,

Thibault, L.,

Slack, T., \&

Kikulis, L. M. (1996, July).

Values and organizational stucture. Human Relations, 49(7), 885-916.

Jepperson, R. L. (1991).

Institutions, institutional effects, and institutionalism. In W. Powell, \& P. J. DiMaggio (Eds.). The new institutionalism in organizational analysis. Chicago: University of Chicago Press.

Kiun, E.-H. (2001, May).

Rules as institutional context for decision making in networks: the approach to postwar housing districts in two cities. Administration \& Society, 33(2), 133-164.

Knights, D. (1992, July).

Changing spaces: the disruptive impact of a new epistemological location for the study of management. Academy of Management Review, 17(3), 514-536.

Knoke, D. (1994).

Political Networks: the structural perspective. Cambridge: Cambridge University Press.

Knoke, D., \&

Burt, R. (1983).

Prominence. In R. S. Burt, \& M. J. Minor (Eds). Applied network analysis: a methodological introduction. California: Sage Publications.
Knoke, D., \&

Laumann, E. (1982).

The social organization of national policy domains: an exploration of some structural hypotheses. In P. Marsden, \& N. Lin (Eds.). Social structure and network analysis. California: Sage Publications.

Laat, P. de (1999).

Research and development alliances: ensuring trust by mutual commitments. In M. Ebers (Ed.). The formation of inter-organizational networks. New York: Oxford University Press.

Leblebici, H., Salancik, G. R., Copay, A., \& King, T. (1991, September).

Institutional change and the transformation of interorganizational fields: an history of the U.S radio broadcasting industry. Administratie Science Quarterly, 36(3), 333-363.

Leuenberger, C., \&

Pinch, T. (2000).

Social construction and neoinstitutional theory: response to Bowring Journal of Management Inquiry. Organization Behavior, 9(3), 271-273.

Li, S.X.,

Berta, \&

W. B. (2002).

The ties that bind: strategic actions and status structure in the US investment banking industry. Oganization Studies, 3(23), 339-368.

Lin, N. (2001).

Social capital: a theory of social structure and action. Cambridge: Cambridge University Press. 
Lomi, A., \&

Grandi, A. (1999).

The network structure of inter-firm relationships in the southern italian mechanical industry. In M. Ebers (Ed.). The formation of interorganizational networks. New York: Oxford University Press.

Luke, T. W. (1999).

Environmentaly as green governmentaly. In E. Darier (Ed.). Discourses of the environment. Massachusetts: Blackwell Publishers.

Machado-da-Silva, C. L., \&

Fonseca, V. S. da (1996, dezembro).

Competitividade organizacional: uma tentativa de reconstrução analítica. Organizações e Sociedade, 4(7), 97 114.

Machado-da-Silva, C. L., \&

Coser, C. (2004a).

Argumentos estruturais para explicação do isomorfismo mimético em um campo organizacional. Anais do Encontro de Estudos Organizacionais, São Paulo, SP, 3.

Machado-da-Silva, C. L., \&

Coser, C. (2004b).

Organização Focal e Relações de Poder em um Campo Organizacional. Anais do Encontro Nacional de Pós Graduação em Administração, Curitiba, PR., 28.

Machado-da-Silva, C. L.,

Fonseca, V. S., \&

Crubellate, J. M. (2005, maio).

Estrutura, agência e interpretação: elementos para uma abordagem recursiva do processo de institucionalização. Revista de
Administração Contemporânea, $9\left(1^{\mathrm{a}}\right.$ Edição Especial), 9-39.

Maillat, D. (1996).

Regional productive systems and innovative miliex. In OECD. Networks of enterprises and local development: competing and co-operating in local productive systems. Paris: Author

March, J.,

Olsen, J. (1989).

Rediscovering institutions: the institutional basis of politcs. New York: Free Press.

Marsden, P. V., \&

Friedkin, N. E. (1994).

Network Studies of social influence. In S. Wasserman, \& J. Galaskiewicz (Eds.). Advances in Social Networks Analysis: research in the social and behavioral sciences. London: Sage.

Meyer, J. W., \&

Rowan, B. (1977, September).

Institutionalized organizations: formal structures as myth and ceremony. American Journal of Sociology, 83(2), 341-363.

Mitchell, J. C. (1976).

The Concept and use of social networks. In W. M. Evan (Ed.) Interorganizational relations. Pensilvania: University of Pensilvania Press.

Mizruchi, M. S., \&

Fein, L. C. (1999, December).

The social construction of organizational knowledge: a study of the uses of coercive, mimetic, and normative isomorphism. Administrative Science Quarterly, 44(4), 653-683. 
Mizruchi, M. S., \&

Galaskiewicz, J. (1994).

Networks of interorganizational relations. In S. Wasserman, \& J. Galaskiewicz (Eds.). Advances in Social Networks Analysis: research in the social and behavioral sciences. London: Sage.

Morgan, G. (1996).

Imagens da organização. São Paulo: Atlas.

Oliver, A., \&

Ebers, M. (1998).

Networking network studies: an analysis of conceptual configurations in the study of inter-organizational relationships. Organization Studies, 4(19), 549-583.

Oster, S. (1990).

Modern competitive analysis. New York: Oxford University Press.

\section{Park, S. H., \&}

Ungson, G. R. (2001, January/February). Interfirm rivalry and managerial complexity: a conceptual framework of alliance failure. Organization Science, 12(1), 37-53.

Pattison, P. (1994).

Social cognition in context: some applications of social network analysis. In S. Wasserman, \& J. Galaskiewicz (Eds.). Advances in social networks analysis: research in the social and behavioral sciences. London: Sage.

Pfeffer, J. (1982). Organizations and organization theory. Boston: Pitman.
Powell, W. W. (1991).

Expanding the scope of institutional analysis. In W. Powell, \& P. J. DiMaggio (Eds.). The new institutionalism in organizational analysis. Chicago: University of Chicago Press.

Ring, P. S., \&

Van de Ven, A. H. (1994, January).

Developmental processes of cooperative interorganizational relationships. Academy of Management Review, 19(1), 90-118.

Scott, J. (2000).

Social network analysis: a handbook (2nd ed.). London: Sage Publications.

Scott, W. R. (1994).

Institutions and organizations: toward a theoretical synthesis. In W. R. Scott, \& J. W. Meyer (Eds.). Institucional environments and organizations: structural complexity and individualism. London: Sage Publications.

Scott, W. R. (1995).

Institutions and organizations. London: Sage Publications.

Scott, W. R. (1998).

Organizations: rational, natural, and open systems (4th ed.). Upper Saddle River: Prentice-Hall.

Sheppard, E. (2002, July).

The spaces and times of globalization: place, scale, networks, and positionality. Economic Geography, 78(3), 307-330. 
Smith, K. G.,

Carroll, S. J., \&

Ashford, S. J. (1995, February).

Intra-and interorganizational cooperation: toward a research agenda. Academy of Management Journal, 38(1), 7-23.

Spink, M. J. P. (1999).

Práticas discursivas e a produção de sentidos. São Paulo: Cortez.

Stevenson, W., \&

Greenberg, D. (2000, December).

Agency and social networks: strategies of action in a social structure of position, opposition, and opportunity. Administrative Science Quarterly, 45(4), 651-678.

Stuart, T. E. (1999, June).

Interorganizational endorsements and the performance of entrepreneurial ventures. Administrative Science Quarterly, 44(2), 315-349.
Townley, B. (1993, July).

Foulcault, power / knowledge, and its relevance for human resource management. Academy of Management Review, 18(3), 518-545.

Walker, M. E.,

Wasserman, S., \&

Wellman, B. (1994).

Statistical models for social support networks. In S. Wasserman, \& J. Galaskiewicz (Eds.). Advances in social networks analysis: research in the social and behavioral sciences. London: Sage.

Wasserman, S., \& Faust, K. (1999).

Social network analysis: methods and applications. Cambridge: Cambridge University Press. 